\title{
High cervical cord injury after accidental pencil stab
}

Sir,

Penetrating injuries of the spine are uncommon in most parts of the world except in South Africa. ${ }^{[1]}$ Commonly used weapons are knives, bicycle spokes, ice-picks, and screwdrivers. Most of the pencil injuries have been reported to occur in or around the orbital region..$^{[2,3]}$ There has been a report of vertebral body granuloma of the cervical region following a pencil stab injury ${ }^{[4]}$ but we could not find any mention of cervical spinal cord injury from a pencil stabbing.

A 7-year-old male was brought into emergency services after falling over a writing pencil when he was hit by his teacher in the school. He was injured in the upper lateral aspect of the neck on the right side. The tip of the pencil entered through the skin just below the right mastoid process. The pencil was immediately withdrawn and there was no breakage of the pencil tip. The patient developed right upper and lower limb weakness with a cerebrospinal fluid (CSF) leak from the punctured neck wound. After admission ( 24 hours after the injury) he complained of neck pain and fever. A neurological examination showed an alert and co-operative boy with right upper and lower limb pyramidal weakness, he in addition also had weakness of the right trapezius and sternomastoid muscles. There was no sensory impairment. Active neck movements were mildly painful but within normal range.

Plain X-rays of the craniovertebral junction and cervical spine were normal. Magnetic resonance imaging (MRI) of the cervical spine showed an intramedullary hyperintense signal at the $\mathrm{C}_{1}-\mathrm{C}_{2}$ level suggestive of cord contusion. The paraspinal tissue on the right side showed a hyper intense signal in the $T_{1}$ weighted image due to the soft tissue edema [Figure 1]. Within 72 hours of antibiotic therapy, the boy became afebrile but remained hemiplegic. The CSF leak stopped within 48 hours. Gradually, he improved and motor power improved to Grade 3/5 in 2 weeks. At the follow-up visit 6 weeks later, the power had improved to Grade 4/5 with some spasticity and the patient was walking without support.

Data regarding pencil lead injuries of the cervical spine are unavailable. Common entry sides of pencil lead injuries include the lower, outer region of the orbit and the inner canthus. Our case of accidental pencil stab injury of the spinal cord causing cord contusion is thus unique. 


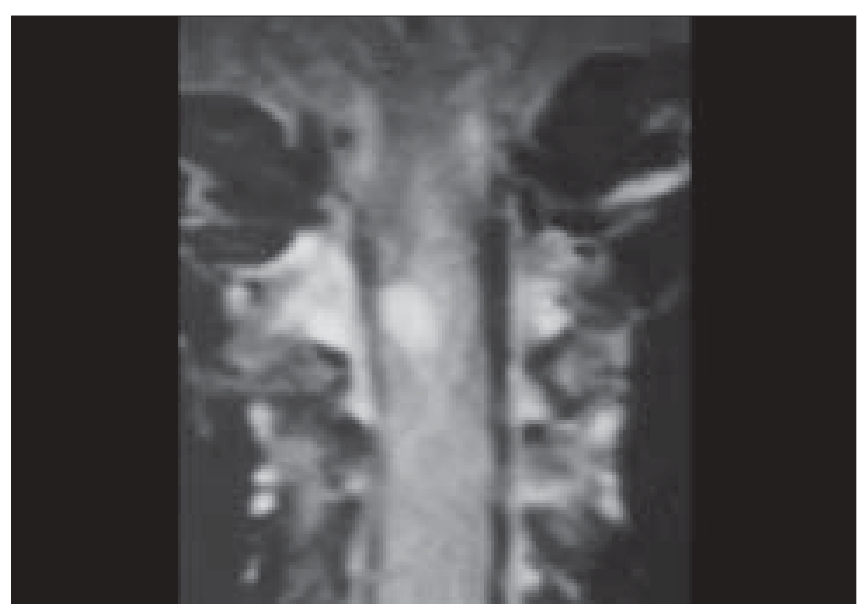

Figure 1: $T_{1}$ weighted coronal image of the cervical spine demonstrating a hyperintense intramedullary signal $A T C_{1}-C_{2}$ level

The spinal cord may be injured directly by the weapon or by indriven bony fragments. The damage to the cord may be either direct or indirect due to impaired arterial supply or venous drainage with resulting hemorrhage or edema. ${ }^{[1,5]}$ The indriven fragment of the weapon may cause a foreign body granulomatous reaction ${ }^{[3]}$ or may act as a micro-traumatizing agent ${ }^{[6]}$ and cause delayed neurological damage. CSF leaks occur in 4 to $6 \%$ of the cases and in most instances it is transient. Approximately one-third of the patients present with a complete transaction of the cord and the remaining patients present with partial cord injury with varying forms of Brown-Sequard syndrome. ${ }^{[6]}$ Our patient had a pure motor deficit.

Treatment consists of local debridement, antibiotics, and antitetanus gammaglobulins. Immediate spinal exploration is generally not necessary except when there is a retained portion of the weapon or when indriven bony fragments cause neural compression. ${ }^{[6]}$ Sepsis (epidural or intradural abscess), granuloma formation, or persistent CSF leak also merit surgical exploration. ${ }^{[4,6]}$ In the present case, the patient recovered with conservative treatment by antibiotics. The absence of a retained broken fragment was fortunate for the child.

A. K. Sinha, S. Adhikari, S. K. Gupta Department of Neurosurgery, Postgraduate Institute of Medical Education and Research, PGIMER, Chandigarh 160 012, India.

E-mail: drguptasunil@gmail.com

DOI: 10.4103/0028-3886.51305
3. Ildan F, Bagdatoglu H, Bovar B, Doganay M, Cetinalp E, Karadayi A. The nonsurgical management of a penetrating orbitocranial injury reaching the brain stem: Case report. J Trauma 1994;36:116-8.

4. Meltzer HS, Kim PJ, Ozgur BM, Levy ML. Vertebral body granuloma of the cervical region after pencil injury. Neurosurgery 2004;54:1527-30.

5. Wolf SM. Delayed traumatic myelopathy following transfixation of the spinal cord by a knife blade. J Neurosurg 1973;38:221-5.

6. Lipschitz R. stab wounds of the spinal cord. In: Vinken PJ, Bruyen GW, editors. Handbook of clinical neurology. Vol 25. Part 1. Amsterdam: North Holland publishing Co; 1976. p. 199-207.

Accepted on 12-03-2009

\section{Ref erences}

1. Cabezudo JM, Carrillo R, Areitio E, Garcia de Sola R, Vaquero J. Accidental stab wound of the cervical spine in front. Acta Neurochir (Wien) 1980;53:175-80.

2. Herman TE, Shackelford GD, Tychsen L. Unrecognized retention of intraorbital graphite pencil fragments: The role of computerized tomography. Pediatr Radiol 1995;25:535-7. 